\title{
Improving irrigation systems conserves water in greenhouse-grown cut flowers
}

\author{
Kurt Schulbach 」 Steve Tjosvold J Danyal Kasapligil
}

\begin{abstract}
In our evaluation of three microirrigation systems used in greenhouse cut-flower production, the systems' ability to apply water uniformly varied widely. The most common irrigation system, the perimeter system, generally applied water less consistently than other tested systems. Center riser and drip irrigation systems generally applied water more uniformly than the perimeter system. And while many perimeter irrigation systems could be retrofitted to improve water distribution, all irrigation systems could be improved with a regular maintenance program consisting of flushing rust and other particulates from irrigation pipe, and chemically controlling biological growth in irrigation pipe.
\end{abstract}

Cut-flower and foliage production is a major agricultural industry in Monterey and Santa Cruz counties with more than 25 million square feet of greenhouse-grown cut flowers, and 874 acres of field flowers and foliage with a value of over $\$ 60$ million. Conserving water and reducing nitrogen leaching are two important goals of the industry in this environmentally sensitive area adjacent to the National Monterey Bay Marine Sanctuary.

As part of a program to improve water management, the Monterey and Santa Cruz counties Cooperative Extension and Monterey County Water Resources Agency conducted a joint project to evaluate irrigation system effectiveness in applying water efficiently in greenhouse cut-flower production. Following these on-site evaluations, growers received individualized reports that made specific recommendations for improving their irrigation systems. In this article, we draw some conclusions about designing, retrofitting and maintaining irrigation systems that influence the uniformity of those systems.

\section{Irrigation evaluation methods}

In any irrigation system, some crop areas receive more water than other areas. The result is underirrigation in some areas, overirrigation in some areas, or a combination of both. To compensate for this, additional water must be applied to make sure all plants are adequately irrigated. The more uniformly the water is applied, the less water is required to meet the needs of all the plants throughout the irrigated area.

One parameter for quantifying the uniformity of an irrigation system is called the distribution uniformity (DU) measurement. The DU is calculated by measuring flow throughout the irrigation system and is defined as the ratio between the lowest quarter $(25 \%)$ of the measurements and the average of all the measurements. The general criteria for DU values for systems in operation for one or more seasons are: $90 \%$ or greater, excellent; $80 \%$ to $89 \%$, good; $70 \%$ to $79 \%$, fair; and less than $70 \%$, poor. Greenhouse irrigation systems have the potential for uniformity in the good to excellent range.

Our first step in the irrigation evaluation was to obtain a general overview of the operation: the location of the well, the location of the timers, the greenhouse layout and the operation of the irrigation system. Next, we chose three general areas for the collection of the evaluation data: one near the pump, one far from the pump and one at an intermediate location. In each of these areas, pressure and flowrate measurements were taken at the inlets to the laterals (the irrigation pipe that runs down the production bed) and at the ends of these laterals.

In the area near the pump, we collected flow rates at two different pressures so that a discharge exponent for the outlets could be estimated. The discharge exponent is a measure of how the flow from the outlets varies with changes in the operating pressure. The exponent ranges from near zero to a little more than 1 . A low exponent means that the flow from the outlet does not change much with changes in pressure, and therefore water can be applied uniformly even with large differences in pressures throughout the irrigation system. A high exponent, on the other hand, means that the flow varies directly with the pressure, so uniform water application requires uniform pressures.

At the farthest point from the pump, we took extra flow-rate measurements to evaluate the potential for plugging in the system. The combination of the pressure and flow measurements, along with the estimates of the emitter exponent and the amount of plugging, are the primary parameters used to evaluate the overall uniformity of the irrigation system.

We made all of the evaluations on roses and carnations, the most common greenhouse crops in the Monterey Bay region. The general layout consists of a center aisle down the middle of the greenhouse ranges, with flowerbeds extending out from the center aisle to the edges of the greenhouse. Flowerbeds are typically 3 feet wide, with a 2 -foot-wide walkway be- 
tween beds for access to the flowers for picking, pruning, and so on. The length of these beds and associated irrigation laterals vary from 100 to 180 feet.

\section{Evaluating irrigation systems}

We evaluated three main types of irrigation systems: 16 perimeter spray systems, three center riser systems and four drip systems. Perimeter spray systems are the most common in the region and designs vary widely. In general, the systems tested consisted of 3/4-inch PVC pipe around the perimeter of each of the flowerbeds with half-circle sprayers directed toward the center of the bed. In some systems, the spacing of the sprayers was as close as 16 inches, and in other greenhouses, the spacing was as far as 30 inches apart. Sprayer flow rate averaged 15 gallons per hour at 15 psi. Inlets to these perimeter systems were either in the middle of the bed or at the aisle end of the bed. In some systems, each bed was controlled by a manual valve at the aisle, and in other systems, a group of beds was controlled by an automatic valve and an irrigation timer.

The center riser systems consisted of a single line of 3/4- or 1-inch PVC

\begin{tabular}{|c|c|c|c|}
\hline System type & $\begin{array}{c}\text { Distribution } \\
\text { uniformity (DU) }\end{array}$ & $\begin{array}{c}\text { Pressure } \\
\text { range }\end{array}$ & $\begin{array}{c}\text { Degree of } \\
\text { plugging }\end{array}$ \\
\hline & $\%$ & psi & \\
\hline Drip & 96 & $35-35$ & Very Low \\
\hline Drip & 95 & $34-38$ & Very Low \\
\hline Perimeter Spray & 90 & $6.5-8.5$ & Medium \\
\hline Drip & 89 & $34-37$ & Low \\
\hline Perimeter Spray & 88 & $6.5-7$ & Medium \\
\hline Center Riser & 87 & $26-33$ & Very Low \\
\hline Center Riser & 87 & $26-39$ & Very Low \\
\hline Perimeter Spray & 84 & $13.5-17$ & High \\
\hline Center Riser & 80 & $9.5-14$ & Very Low \\
\hline Perimeter Spray & 76 & $5-9$ & Very Low \\
\hline Perimeter Spray & 73 & $2-4$ & Low \\
\hline Perimeter Spray & 72 & $9-10$ & Medium \\
\hline Perimeter Spray & 72 & $7-11$ & Low \\
\hline Perimeter Spray & 69 & $3-12$ & Very Low \\
\hline Perimeter Spray & 69 & $9.5-12$ & High \\
\hline Perimeter Spray & 69 & $2-4$ & Low \\
\hline Perimeter Spray & 69 & $4-14.5$ & Low \\
\hline Perimeter Spray & 64 & $4-7$ & Medium \\
\hline Drip & 64 & $4-7$ & High \\
\hline Perimeter Spray & 62 & $4.5-13$ & High \\
\hline Perimeter Spray & 57 & $14-35$ & High \\
\hline Perimeter Spray & 56 & $16-26$ & High \\
\hline Perimeter Spray & 51 & $8-15$ & High \\
\hline
\end{tabular}

pipe down the center of each bed. Full circle sprayers were mounted on 18inch risers, spaced from 5 to 7 feet apart. The sprayer flow rate averaged 37 gallons per hour at 15 psi. These systems are commonly used in rose growing, but are not used in carnation growing where the foliage is too thick to allow good coverage.

The drip systems that were evaluated use various drip products including heavy wall tape with pressurecompensating emitters, heavy wall tubing with turbulent flow emitters and porous wall tape. Common configurations consisted of four lines of drip tape per bed for carnations, and two lines of drip tubing per bed of roses. Flow rates for tape were 0.22 or 0.45 gallons per minute per 100 feet at 10 psi. Flow rates for tubing were 0.7 or 1.0 gallons per minute per 100 feet at 15 psi. The tape was used with carnations, while heavy wall tubing was installed for roses because the thorns would easily damage the tape.

\section{Distribution averages $\mathbf{7 5} \%$}

Microirrigation systems used in greenhouse cut-flower production should attain a DU of over $85 \%$. However, in this survey, the average DU was only $75 \%$ and ranged as low as $51 \%$ (table 1 ). The lower the DU, the more water is required to meet crop needs. The amount of extra water needed to ensure adequate irrigation could be estimated by dividing the water requirement by the DU. Relative to a system with a perfect $100 \%$ uniformity, a system with a DU of $85 \%$ requires about $18 \%$ more water than the crops need to make sure that the drier areas receive enough water $(1.0 / 0.85$ $=1.18$ ). An irrigation system with a DU of $51 \%$ would require nearly $70 \%$ more water than one with a uniformity of $85 \%$. Often, this amount of extra water is not applied, and in some areas, there may be yield losses due to water stress. In other areas, yields may be reduced due to the

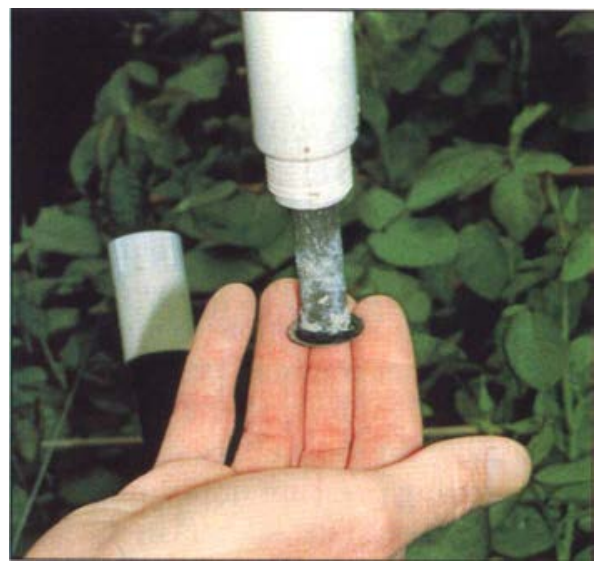

Inexpensive screens can help keep forelgn materials such as sand and rust flakes out of the sprayer lateral. In this photo, pipe joint compound collected in the filter after a new irrigation system was installed.

leaching of fertilizer caused by overirrigation.

\section{Pressure lost to friction}

In general, the flow rates in the perimeter systems evaluated were too high for the 3/4-inch laterals, causing large friction losses. The average DU was only $70 \%$. In one system, the pressure was 75 psi at the pump but only 2 psi at the end of the sprayer lines. This pressure drop was caused by friction losses through valves and pipe bends, and in small diameter pipe. This is a substantial waste of energy.

While large pressure losses increase the cost of energy for pumping, large pressure losses in the mainlines do not necessarily result in low distribution uniformity. Large friction losses in mainlines can be compensated for by using pressure regulators that even out the water flow to each separately controlled area. Another way to compensate for large pressure losses in the mains is to adjust the irrigation set times. For example, in areas of the greenhouse where pressures are low, the run time can be increased until the total amount of water applied to the irrigation block is the same as in the high-pressure areas.

However, pressure losses in the laterals cannot be compensated for and, in the worst case, large friction losses resulted in the plants at the end of the bed receiving only $50 \%$ of the water that the plants near the inlets received. There are many ways to improve the pressure uniformity in the laterals. One simple, low-cost method is to re- 
place the sprayers with ones that have smaller orifices. This would reduce the flow rate and corresponding friction loss and increase the pressure uniformity. However, smaller sprayer orifices are more susceptible to plugging. This is another common problem in the microirrigation systems tested.

Possibly the most effective method of improving pressure uniformity is to place the inlet to the laterals in the center instead of at the end. In a typical design, a 160-foot lateral with the inlet at the end would have a pressure loss of $44 \%$ from one end to the other, while the pressure loss would only be $10 \%$ if the inlet were at the middle of the bed (fig. 1). About half of the systems evaluated had the inlets at the center of the lateral. In this example, moving the inlet to the center could increase the uniformity enough to reduce the irrigation water requirement by $20 \%$. However, this would require automatic valves because of the difficulty in manually turning on the valves when they are located in the middle of the plant rows. In most systems, friction losses can also be reduced and uniformity raised by increasing the diameter of the laterals, from 3/4-inch to 1 inch.

\section{Assessing center riser systems}

Of the three center riser systems we examined, all had high levels of uniformity, with an average DU of $85 \%$. The sprayers themselves had excellent uniformity and most of the reduction in DU was caused by pressure differences along the mainline. In one system, the pressure-regulating control valves along the mainline were not set

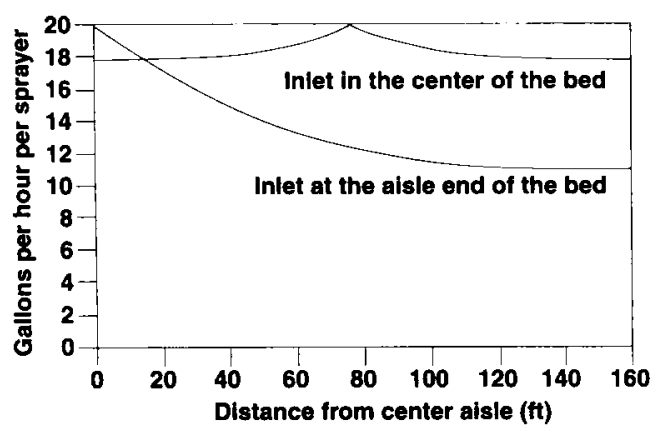

Fig. 1. Distribution of flow rates along a lateral, comparing inlet placed at aisle to inlet placed in center of bed.

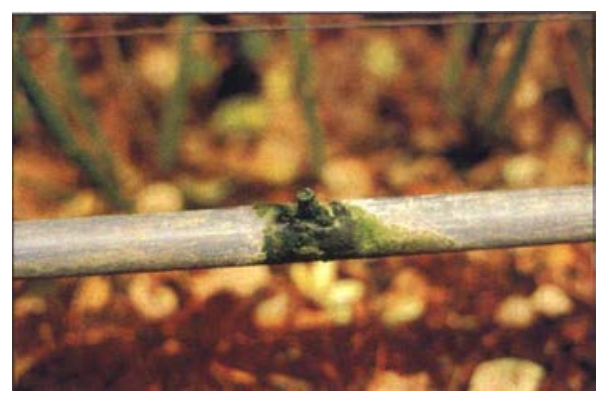

Occasional water treatment may be necessary to keep algae and chemical deposits from plugging the sprayers.

at uniform pressures. If these valves had been set correctly, the DU in this system could have been as high as $95 \%$. In two of these systems, the spray laterals were $3 / 4$-inch PVC, which is slightly undersized for the flow rate used. In the other system, the first half of the lateral was 1 inch and the second half was 3/4-inch line. This is a good design principle that could be used in these systems, and the perimeter systems, to provide good pressure uniformity at a lower cost than if 1-inch line is used throughout.

\section{Evaluating drip systems}

One of the drip systems with pressure compensating emitters was a new installation and the other was 3 years old. The emitter exponent of both these systems was about .08, indicating that emitter flow rates change little with changes in pressure. The new system had a DU of $95 \%$ and the older system had a DU of $89 \%$. Both of these systems had few plugging problems, and the slightly lower DU of the older system was probably due to age. Pressure-compensating emitters use a rubber diaphragm, or some type of flexible orifice, that can wear out over time. However, even though the emitters showed some wear, the pressure compensation of these emitters was still working as well as in the new installation.

The new installation featured a system with turbulent flow emitters and had a uniformity of $96 \%$. Turbulent flow emitters typically have an exponent of about 0.5 , indicating that they are somewhat pressure compensating, and they have fewer plugging problems than orifice emitters, such as the sprayers in the perimeter spray systems. Because of the short runs and low flow rates of the emitters, there was no measurable pressure loss in the laterals (less than $1 \mathrm{psi}$ ). The high DU of the system was due to the very small pressure differences and the fact that turbulent flow emitters can be manufactured with low variance in flow rates.

The porous wall tape had too high a flow rate and excessive friction losses. The emitter exponent for porous wall tape was near 1 , which resulted in the flow rate changing almost directly with changes in pressure. Because of the large emitter exponent, the flow rates decreased significantly from the inlet to the end of the lateral. Porous wall tape is also subject to plugging problems. Silt and clay particles that pass through most irrigation filters tend to plug up the small pores in the tape walls. Because there is no way to treat this plugging unless the water is very clean, plugging can be a major problem in these systems. As a result of the high emitter exponent and the plugging problems inherent in porous tape, the DU in this system was only $64 \%$.

\section{Performance must be measured}

On average, the greenhouse irrigation systems evaluated rated only "fair," and 10 of the 23 systems rated "poor." While most flower growers are observant, irrigation system performance is not something that can easily be seen; it must be measured and quantified. Once the results of the evaluations were shown to the growers, they were quick to make improvements, such as resetting pressure regulators or adjusting automatic timers.

Unfortunately, one major cause of low DU in many systems is that pipe sizes are too small for the application rates used. This problem cannot be solved without some expensive retrofitting of the systems. Generally, in retrofitting or in new installations, lateral pipe diameter could be increased from 3/4-inch to 1 inch and the lateral inlet could be placed in the middle instead of at the end of the bed. Some systems could economize by using 1 -inch lines in the first half of the bed and 3/4-inch pipe for the last half of the bed. An-

(continued on page 48 ) 


\section{Index}

The following are research articles, news stories and editorials appearing in California Agriculture, Volume 52, Numbers 1 through 6, January through December 1998. Back issues may be purchased for \$3 per copy, while supplies last.

\section{Research articles}

ECONOMICS AND PUBLIC POLICY

Conflicts arise on the urban fringe - Handel May-Jun p11

${ }^{\star}$ Rural dwellers divided on how to head off urbanization - Handel, Sokolow May-Jun p14

Méthod champenoise sparkling pear wine costs most, but offers highest quality McGourty, Butzke Nov-Dec p37

Feasibility of producing pear wine .. . Pears produce premium sparkling wine McGourty, Butzke Nov-Dec p31

Land trusts conserve California farmland Vink May-Jun p27

North Bay leads Central Valley in protecting farmland - Sokolow May-Jun p17

Permissive growth policies may encourage speculative investment in farmland Moore May-Jun p23

SPECIAL SECTION: Biotechnology

Public germplasm development at a crossroads: Biotechnology and intellectual property - Wright Nov-Dec p8

Perspective

Statewide farmland protection is fragmented, limited - Sanders May-Jun p5 *Urban growth squeezes agriculture Medvitz May-Jun p8

\section{FOOD AND NUTRITION}

Latinos improve food habits through nutrition education - Kaiser et al. Jul-Aug p32

HUMAN AND COMMUNITY DEVELOPMENT

Media campaigns promote driver safety for farmworkers - Grieshop et al. Jan-Feb p11

\section{LAND, AIR AND WATER SCIENCES}

Cracks affect infiltration of furrow crop irrigation - Hanson, Fulton, Goldhamer Mar-Apr p38

Earlier irrigation cutoff for sugarbeets conserves water - Kaffka, Peterson, Kirby Jan-Feb p21

Innovative strategies reduce selenium in Grasslands drainage - Quinn McGahan, Delamore Sep-Oct p12

New crop coefficients estimate water use of vegetables, row crops - Grattan et al. Jan-Feb p16

Subsurface drainage systems have little impact on water tables, salinity of clay soils - Grismer, Bali Sep-Oct p18

Though difficult to achieve, revegetation is best way to stabilize soil - Grantz et al. Jul-Aug p8
Water turbulence disrupts accuracy of some flow meters - Hanson, Schwank।

Jan-Feb p25

Wind barriers offer short-term solution to fugitive dust - Grantz et al. Jul-Aug p14

\section{NATURAL RESOURCES}

Biological control of the blue gum psyllid proves economically beneficial Dahlsten et al. Jan-Feb p35

\section{PEST MANAGEMENT}

Bats feed on crop pests in Sacramento Valley - Long et al. Jan-Feb p8

Beneficial insects move from flowering plants to nearby crops - Long et al. Sep-Oct p23

SPECIAL SECTION: Biotechnology

Transgenic Bt crops and resistance...Broadscale use of pest-killing plants to be true test - Federici Nov-Dec p14

Can cover crops reduce vine vigor, leafhopper abundance in vineyards? Daane, Costello Sep-Oct p27

Celery petiole lesion damage caused by insecticide - Koike et al. Jul-Aug p36

Fungal pathogen controls thrips in greenhouse flowers - Murphy et al

May-June p32

tGrape growers report losses to black-foot and grapevine decline - Scheck et al. Jul-Aug p.19

Insect-transmitted viruses threaten agriculture - Gilbertson et al. Mar-Apr p23 "CCPP: preventive medicine for citrus - Gumpf Mar-Apr p27

Invasion biology: Rethinking our response to alien species - Venette, Carey Mar-Apr p13

IPM helps control elm leaf beetle Dahisten et al. Mar-Apr p18

Modified bait tube controls disease-carrying ticks and fleas - Lane et al. Mar-Apr p43

*Lyme disease basics - Mar-Aprp43

Native gray ant has beneficial role in peach orchards - Daane, Dlott Nov-Dec p25

Parasitoid wasp controls blue gum psyllid - Dahisten et al. Jan-Feb p31

Persistent silverleaf whitefly exploits desert crop systems - Toscano et al. Mar-Apr p29

Pest management record-keeping duties shift with computerization - Flint et al. Jul-Aug p27

Ravenous Formosan subterranean termites persist in California - Rust et al. Mar-Apr p34

Success of mite-fighting tactics evaluated - Karban, Zalom Nov-Dec p21

Varroa mite impacts Africanized bee spread and beekeeping - Page Mar-Apr p9

\section{PLANT SCIENCES}

†Curly top virus found in perennial shrubs in foothills - Davis et al. Sep-Oct p38

Legumes show success on Central Coast rangeland - Weitkamp, Graves May-June p37
Pyrithiobac sodium controls nightshade without long-term effect on cotton Vargas et al. Sep-Oct p34

Verticillium survives heat in Mojave Desert alfalfa - Erwin, Howell Jul-Aug p24

\section{News departments}

Outreach news

"City Bugs" website turns teens into taxonomists - Jan-Feb p4

UC trains welfare recipients - Jan-Feb p5

Research update

Bats can pack a punch in pest control Jan-Feb p6

Center for Exotic Pest Research tackles controversy - Mar-Apr p5

Growers strive to reduce selenium discharges - Sep-Oct p10

Introduction: Exotic pests - Mar-Apr p5

Lizards slay Lyme disease spirochetes Mar-Aprp4

Scientists score dustbusting efforts in Antelope Valley - Jul-Aug p6

Scientists see spike in Africanized bee numbers - Mar-Apr $\mathrm{p} 7$

Silverleat whitefly extends range Mar-Apr p6

Summer boating main source of lake's MTBE - Jul-Aug p7

UC contributes biotech breakthroughs -Nov-Dec p6

Science briefs

Bison disease still threatens cattle Jan-Feb p6

Change in law allows transgenic cotton Nov-Dec $\mathrm{p} 5$

50 Years: Veterinary Medicine -- Sep-Oct p6

Imported fire ant elicits tempered concern - Sep-Oct $\mathrm{p5}$

Insect quarantine facility breaks ground Jul-Aug p5

New phylloxera may threaten nurseries -Nov-Dec p4

NRS receives $\$ 4$ million - Jul-Aug p5

Plants detoxify chromium - Sep-Oct p5

Rust disease shrinks garlic crop - Jul-Aug p4

Scientists look at kids' pesticide exposure - Sep-Oct p5

UC, COS, high school to build dairy Nov-Dec p4

\section{Editorials}

Times and programs change, but Division carries on tradition of public service Gomes Jan-Feb

New facilities to foster solutions for exotic pests - Gomes Mar-Apr

Steering a course to farmland protection Sokolow May-Jun

Potpourri: New strategies, funding, partnerships - Gomes Jul-Aug

Veterinary medicine: Mandates and missions for the 21st century - Osburn Sep-Oct

Biotechnology: New benefits, new questions - Qualset, Webster Nov-Dec

*Sidebars.

†New pests and plant diseases articles 


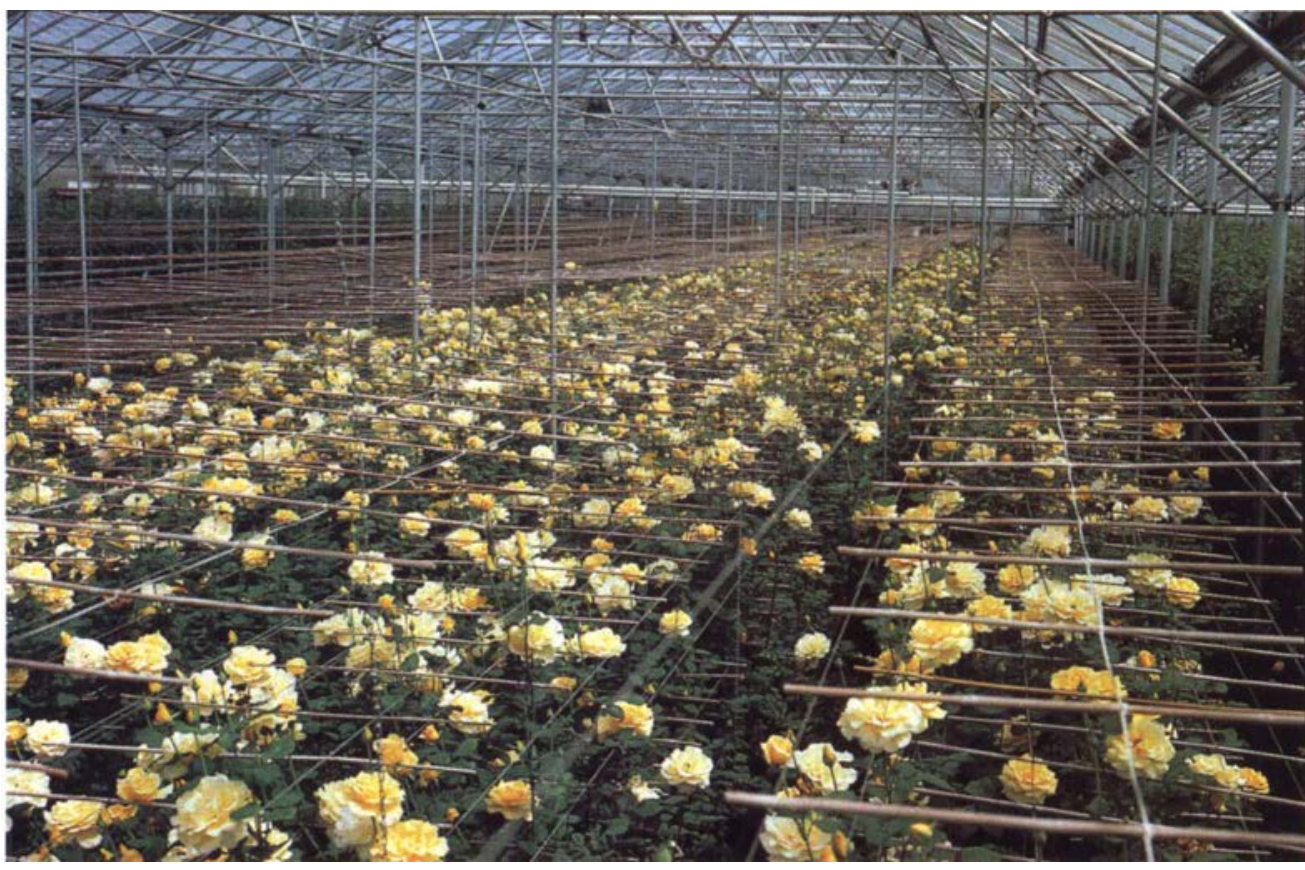

Commercial cut-rose production in a coastal California greenhouse. Irrigation water applied uniformly to production beds can enhance production and quality of the rose crop and help to conserve water.

(continued from page 46)

other solution is to install drip irrigation, which, in our survey, can provide excellent irrigation uniformity without plugging. The lower operating costs resulting from higher uniformity, lower operating pressure and reduced fertilizer needs could make retrofitting some systems economical.

Growers need to have a better understanding of irrigation system design and how it relates to total operating costs so they can make informed decisions when retrofitting their system or when selecting the design of a new irrigation system.

Although not quantified in this survey, it is apparent that timing devices rather than manual operation of sole- noids could significantly improve uniformity. It was noted many times that a worker operating the solenoid valves was distracted and thus not keeping an eye on the timing of the irrigation. Although not common, pressurecompensating valves along water mains, when set properly, could significantly increase uniformity.

Plugging of the outlets was the other major cause of low uniformity. The mainlines in most of the systems were iron pipe and, as a result, rust flakes were often found plugging emitters. Chemical precipitates and sand were often the cause of plugging in other systems. Only the drip systems used water filtration, and the overall higher uniformity of these sys- tems demonstrates the value of filtration. A regular maintenance program including chemical treatment and flushing of the laterals will also help keep systems clean and reduce plugging without the damage often caused by manual cleaning.

Uniform water application does not guarantee a high level of irrigation efficiency because it is still possible to apply too much water even if water is applied uniformly. The grower, in addition, must learn the water-use requirement of the crop and the irrigation system's application rate, to estimate the correct amount of water to apply.

K. Schulbach was Farm Advisor, UCCE Monterey County, and currently is Doctoral Graduate Student, University of Florida, Gainesville, Fla.; S. Tjosvold is Farm Advisor, UCCE Santa Cruz County and D. Kasapligil was Hydrologist, Monterey Country Water Resources Agency, and currently is Agronomist, Dellavalle Laboratory Inc., Fresno.

\section{Further reading}

Fereres E, Alijibury F, Beutel J, et al. 1981. Drip irrigation management. Division of Agricultural Sciences, University of California leaflet 21259. $44 \mathrm{p}$

Hanan J. 1998. Greenhouses: Advanced Technology for Protected Horticulture. CRC Press, Boca Raton, Fla., Chapter 5: water: p. 271-385

Schwankl L, Hanson B, Prichard T. 1993. Low-volume Irrigation. Cooperative Extension, Department of Land, Air, and Water Resources, University of California, Davis. $116 \mathrm{p}$.

Tjosvold S, Schulbach K. 1991. How to reduce water use and maximize yields in greenhouse roses. Cal Ag 45(3): 31-2.

\section{CALIFORNIA AGRICULTURE ASSOCIATE EOITORS}

\section{Animal, Avian, Aquaculture}

\& Veterinary Sciences

Jim Cullor

Christopher M. Dewees

Kathryn Radke

Barbara A. Reed

Economics \& Publlc Policy

George Goldman

Richard A. Howitt

Alvin Sokolow
Food \& Nutrition

Amy Block Joy

Eunice Williamson

Human \& Community

Development

Linda M. Manton

Karen P. Varcoe

Land, Air \& Water Sciences

John Letey

Henry J. Vaux, Jr.
Natural Resources

Daniel W. Anderson

Lynn Huntsinger

Richard B. Standiford

Pest Management

Michael K. Rust

Robert Washino

Plant Sciences

Jodie S. Holt

Lee F. Jackson

G. Steven Sibbett http://danr.ucop.edu/calag/

CALAG@ucop.edu

PH: (510) 987-0044

FAX: (510) 465-2659 